\title{
Localization of Reduced Nicotinamide Adenine Dinucleotide Oxidase Activity in Acholeplasma and Mycoplasma Species
}

\author{
J. DENNIS POLLACK \\ Department of Medical Microbiology, The Ohio State University, Columbus, Ohio 43210, and The Children's \\ Hospital Research Foundation, Columbus, Ohio 43205

\begin{abstract}
Reduced nicotinamide adenine dinucleotide (NADH) oxidase activity (EC
\end{abstract} \\ 1.6.99.1) was assessed in membrane and supernatant fractions obtained by \\ osmotic lysis and differential centrifugation from Acholeplasma granularum, $A$. \\ modicum, $A$. axanthum, and Mycoplasma strain 14. NADH:ferricyanide ox- \\ idoreductase activity (EC 1.6.99.1) was also assessed in fractions of $A$. laidlawii B \\ and the mycoplasma. NADH oxidase and NADH:ferricyanide oxidoreductase \\ activities were localized in the membrane fraction of the acholeplasmas and in \\ the supernatant fraction of the mycoplasma. The localization of NADH oxidase \\ in membrane fractions of cells of Acholeplasma and supernatant fractions of cells \\ of Mycoplasma after osmotic lysis is useful in differentiating these genera.
}

The genera Acholeplasma and Mycoplasma, in the class Mollicutes, are distinguished by their cholesterol requirement $(5,22,30,33)$. Other properties which appear to be useful in their taxonomic separation are genome size (2, $15)$, sensitivity to digitonin or polyanethol sulfonate $(7,9)$, and their ability to synthesize lipids from acetate (8). Some other features of differential value at the generic level are as follows: sensitivity to amphotericin B or lysolecithin (13, 25 ), nature of their lactic dehydrogenases (17), differences in their neutral lipids and phospholipids (30), and the localization of reduced nicotinamide adenine dinucleotide phosphate (NADPH) oxidase and glucose-6-phosphate dehydrogenase activities $(18,20)$. Organisms in these genera are non-thermophilic and do not hydrolyze urea or exhibit a spiral-like cell morphology.

In our earlier studies (18-20), we provided evidence that the localization of reduced nicotinamide adenine dinucleotide (NADH) oxidase activity (EC 1.6.99.1) is useful in distinguishing these genera. We prepared membrane and supernatant fractions of Acholeplasma laidlawii A and B, then known as Mycoplasma laidlawii A and $\mathrm{B}$, as well as various other Mycoplasma spp. by osmotic lysis and differential centrifugation. In both $A$. laidlawii $\mathrm{A}$ and $\mathrm{B}$, at least $92 \%$ of the activity was found in the membrane fraction, whereas in all other mycoplasmas examined about $94 \%$ of the activity was found in a supernatant fraction after centrifugation $(2 \mathrm{~h}$, $144,000 \times g)$.

The taxonomic usefulness of the localization pattern was limited since $A$. laidlawii was the only recognized species not requiring cholesterol. More recently, other Mollicutes not re- quiring cholesterol have been identified and classified as species of Acholeplasma. In this work we report on the localization of $\mathrm{NADH}$ oxidase activity in these newly recognized species of Acholeplasma and the NADH:ferricyanide oxidoreductase activities in Mycoplasma strain 14 and A. laidlawii B.

\section{MATERIALS AND METHODS}

Organisms. A. granularum BTS-39, A. modicum PG49, and $A$. axanthum $\mathrm{S} 743$ were obtained from J. Tully, National Institutes of Health, Bethesda, Md. Mycoplasma strain 14 was originally obtained from R. C. Cleverdon, University of Connecticut.

Media. Acholeplasmas were grown in a broth medium which was modified from a formula reported earlier (19) by omitting oleic acid. The mycoplasma was grown in a modified liquid Edward medium (18).

Growth, harvest, and preparation of cellular fractions. Organisms were grown in broth culture ( 0.75 to 1.5 liters) for $48 \mathrm{~h}$ at $37 \mathrm{C}$. The broth was inoculated with a 24 -h culture (2 to $10 \%$ volume). Cells were harvested and washed as previously reported (18). Cell fractions were obtained after osmotic lysis and differential centrifugation. The pelleted, washed whole cells from 1 liter of medium were mixed

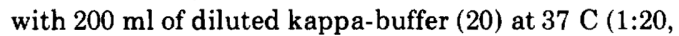
with distilled water). The whole cell suspension was incubated for 15 to $30 \mathrm{~min}$ at $37 \mathrm{C}$, and then centrifuged at $3,000 \mathrm{rpm}$ for $2.5 \mathrm{~min}$ at $4 \mathrm{C}$ (SS34 rotor, Ivan Sorvall, Inc., Norwalk). The pellet was discarded. The supernatant was centrifuged at 19,000 rpm (SS34 rotor) for $40 \mathrm{~min}$ at $4 \mathrm{C}$. The resultant supernatant and pellet were carefully separated and the pellet was reserved. The supernatant was centrifuged at 40,000 rpm for $2 \mathrm{~h}$ (no. 40 rotor, Spinco L, Beckman, Fullerton), and the pellet was discarded. All of these supernatants were passed through 0.20 $\mu \mathrm{m}$ pore size filters; the mycoplasma supernatants were also passed through $0.10-\mu \mathrm{m}$ pore size filters. The filtrates are designated supernatant fraction. 
The reserved pellet, containing membranes and some unlysed cells, was mixed with about $50 \mathrm{ml}$ of 1:20 kappa-buffer $(37 \mathrm{C})$, incubated for $15 \mathrm{~min}$ at $37 \mathrm{C}$, and centrifuged as for whole-cell suspension. The resultant pellet containing the residual whole cells was discarded. The membranes in the supernatant were pelleted by centrifugation at $19,000 \mathrm{rpm}$ (SS34 rotor) for $40 \mathrm{~min}$ at $4 \mathrm{C}$. The membrane-pellet was washed four to six times by centrifugation and was resuspended in 1:20 kappa-buffer. The washed pellet is designated membrane fraction.

Assays. NADH oxidase activity was assessed as previously described (18), but substituting kappabuffer for the originally described B2 buffer (19), sometimes called "beta" buffer. The data are reported as ratios of micromoles of $\mathrm{NADH}_{2}$ oxidized per minute per milligram of membrane fraction of Lowry protein over similar information obtained using the homologous supernatant fraction (membrane fraction/supernatant fraction $(\mathrm{M} / \mathrm{S}])$. The data are the means of three to eight different determinations.

$\mathrm{NADH}$ :ferricyanide oxidoreductase (EC 1.6.99.1) activities of the mycoplasma and $A$. laidlawii $B$ were determined after the procedure of Minakami et al. (14). Preparations were first assayed for $V_{\max }$ $\left(\mathrm{NADH}_{2}\right)$. Reaction mixtures $(3.0 \mathrm{ml})$ contained (in micromoles): $\mathrm{Na}_{2} \mathrm{HPO}_{4}, 75.1 ; \mathrm{NaCl}, 2.3$; tris(hydrox-

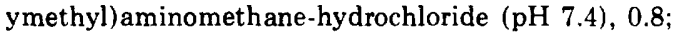
2 -mercaptoethanol, $0.2 ; \mathrm{K}_{3} \mathrm{Fe}(\mathrm{CN})_{8}, 1.7$ or 3.4 ; and various amounts of $\mathrm{NADH}_{2}$. The reaction was started with about 8 to $34 \mu \mathrm{g}$ of cell fraction protein. The $V_{\max }$ in these experiments was about $1.11 \mathrm{mM}$. A concentration of $1.11 \mathrm{mM} \mathrm{NADH}_{2}$ and other ingredients as mentioned above were then used in preliminary experiments to determine the $V_{\max }$ with respect to ferricyanide. At the high concentrations of ferricyanide it was necessary to conduct the assays at 440 or 460 $\mathrm{nm}$ and then calculate for $420 \mathrm{~nm}$ (14). Rates of ferricyanide reduction were determined from data taken within $60 \mathrm{~s}$ after all additions by use of a Beckman DB spectrophotometer equipped with a recorder at a chart speed of 6 inches $(15.24 \mathrm{~cm}) / \mathrm{min} . K_{m}$ was computed by extrapolation.

After preliminary experiments, we decided to use $1.50 \mathrm{mM} \mathrm{NADH}, 2.0 \mathrm{mM} \mathrm{K}_{3} \mathrm{Fe}(\mathrm{CN})_{6}$, and other ingredients as cited above to determine the NADH: ferricyanide oxidoreductase activity in cell fractions.

Protein was determined by the procedure of Lowry et al. (12).

Difference spectra (oxidized minus reduced) of Mycoplasma strain 14 supernatant fraction and $A$. laidlawii B membrane fraction were obtained. Supernatant fractions were concentrated by ultracentrifugation or by suspending in them a dialysis bag containing Aquacide II (Calbio, New York, N.Y.) for about $6 \mathrm{~h}$ at $4 \mathrm{C}$. These concentrates were dialyzed at $4 \mathrm{C}$ against three changes of 1,000 volumes of $0.01 \mathrm{M}$ $\mathrm{Na}_{2} \mathrm{HPO}_{4}(\mathrm{pH} \mathrm{7.6)}$, which was also $8 \mathrm{mM}$ with respect to $\mathrm{NaCl}$.

Difference spectra were obtained at room temperature in a Cary model 11 recording spectrophotometer (Allied Physics, Monrovia, Calif.) equipped with a 0.5 -absorbance (full scale) slidewire, between 400 and $650 \mathrm{~nm}$. Reduced preparations were obtained by gassing, in glass-stoppered cuvettes, with nitrogen ("prepurified," Matheson, Rutherford, N.J.) or carbon monoxide (chemically pure, from the same manufacturer) or by the addition of several crystals of KCN or ascorbic acid with and without $30 \mu \mathrm{mol}$ of $\mathrm{NADH}_{2}$. To obtain other reduced preparations, the following was added to the cuvette prior to stoppering: crystals of $\mathrm{KBH}_{4}, \mathrm{Na}_{2} \mathrm{~S}_{2} \mathrm{O}_{4}$, and formamidine disulfide, hydrate, dihydrochloride (FD), and 1 to $3 \mu \mathrm{mol}$ of 2-n-nonyl-4-hydroxyquinoline- $\mathrm{N}$-oxide (NOQNO) in $0.05 \mathrm{ml}$ of $0.05 \mathrm{~N} \mathrm{KOH}$ (FD and NOQNO, obtained from Sigma Chemical Co., St. Louis, Mo.) as well as 50 to $150 \mu \mathrm{mol}$ of sodium amytal (Merck) in 0.05 to $0.10 \mathrm{ml}$ of $50 \%$ ethanol, $\mathrm{pH} \mathrm{7.6}$. In the case of sodium amytal and NOQNO, an equal amount of either ethanol or $\mathrm{KOH}$, respectively, was added to the unstoppered aerobic cuvette. The reaction mixtures $(3.0 \mathrm{ml})$ contained 11 to $78 \mathrm{mg}$ of cell protein and (in micromoles): $\mathrm{Na}_{2} \mathrm{HPO}_{4}(\mathrm{pH} 7.6), 29.8$ to 31.4 ; and $\mathrm{NaCl}, 24.5$ to 26.2 . Reduced preparations were compared to unstoppered cuvettes containing identical mixtures without reductants, but with a crystal of $\mathrm{K}_{3} \mathrm{Fe}(\mathrm{CN})_{6}$. In some experiments, flavine adenine dinucleotide was added (5 $\mu \mathrm{mol}$, Sigma Chemical Co.), to both "oxidized" and "reduced" cuvettes.

\section{RESULTS}

The M/S ratios of NADH oxidase activity in five Acholeplasma isolates, representing four species, and literature values $(19,20,23)$ of eleven Mycoplasma isolates, representing nine species, are shown in Table 1 . The ratios for the Acholeplasma spp. ranged from about 13 to 763 , and for the Mycoplasma spp. they ranged from 0.01 to 0.23 . The Acholeplasma $\mathrm{M} / \mathrm{S}$ ratios were

TABLE 1. Ratio of NADH oxidase activity in osmotically prepared membrane $(M)$ and supernatant (S) fractions from Mycoplasmatales ${ }^{a}$

\begin{tabular}{lr}
\hline \multicolumn{1}{c}{ Organism } & \multicolumn{1}{c}{ M/S } \\
\hline Acholeplasma laidlawii B (PG9) & 763.22 \\
A. laidlawii A (PG8) & 12.78 \\
A.granularum (BTS-39) & 172.78 \\
A. axanthum (S743) & 25.83 \\
A. modicum (PG49) & 54.13 \\
& \\
Mycoplasma pneumoniae (65-2053) (20) & 0.02 \\
M. pulmonis (N3) (20) & 0.03 \\
M. neurolyticum (PG28) (19) & 0.23 \\
M. bovigenitalium (PG11) (19) & 0.01 \\
M. gallisepticum (S6) (19) & 0.03 \\
M. gallisepticum (A5969) (19) & 0.04 \\
M. hominis (ATCC 14152) (19) & 0.09 \\
M. arthritidis (ATCC 14124) (19) & 0.10 \\
M. arthritidis (H39) (19) & 0.10 \\
Mycoplasma strain 14 (19) & 0.01 \\
M. mycoides (Y) (23) & 0.01 \\
\hline
\end{tabular}

${ }^{a}$ Activity is expressed as micromoles of NADH oxidized per minute per milligram of Lowry protein.

${ }^{b} \mathrm{M} / \mathrm{S}$ ratios are the means from three to eight different batches of organisms. 
from 50 to over 50,000 times higher than those found in the Mycoplasma.

To compare the rates of NADH:ferricyanide oxidoreductase activity, it was necessary to first determine the optimal concentration of reactant $\mathrm{NADH}_{2}$ and ferricyanide. Figure 1 (insert) shows the effect on the velocity of the reaction of varying $\mathrm{NADH}_{2}$ concentration at one of two different ferricyanide concentrations $(0.57$ or $1.13 \mathrm{mM}$ ). In both experiments using the same amount of one supernatant fraction concentrate of Mycoplasma strain 14, the $V_{\max }$ was at about $1.11 \mathrm{mM} \mathrm{NADH}_{2}$. At higher concentrations of $\mathrm{NADH}_{2}$, the velocity was appreciably slower. Figure 1 shows the effect of varying $\mathrm{K}_{3} \mathrm{Fe}(\mathrm{CN})_{6}$ concentrations (at $1.50 \mathrm{mM} \mathrm{NADH}{ }_{2}$ ) on the velocity of the reaction using two different batches of supernatant fraction concentrate. The mean $V_{\max }$ occurred at about $2.0 \mathrm{mM}$ $\mathrm{K}_{3} \mathrm{Fe}(\mathrm{CN})_{6}$. Higher concentrations markedly reduced the velocity of the reaction. At lower concentrations and by extrapolation, two distinct lines were obtained with both preparations. Examination of the steeper pair of these slopes permitted the calculation of an average $K_{m}$ for these preparations of $5.2 \times 10^{-4} \mathrm{M}$; similarly, the second pair of slopes indicated a $K_{m}$ of about $5.3 \times 10^{-5} \mathrm{M}$.

NADH:ferricyanide oxidoreductase activity was determined in membrane and supernatant fractions of $A$. laidlawii $\mathrm{B}$ and the mycoplasma. For comparison, NADH oxidoreductase activity was also determined in the same preparations (Table 2). The data show that NADH:ferricyanide oxidoreductase activity is also localized in the membrane fraction of $A$. laidlawii $\mathrm{B}$ and the supernatant fraction of Mycoplasma strain 14.

Difference spectra assays were essentially negative. No spectrophotometric evidence was found for the presence of any respiratory pigment in either $A$. laidlawii $\mathrm{B}$ membrane or the mycoplasma supernatant fraction concentrates. Flavin-bleaching $(27,28)$ was detected as a slight negative absorbance between 410 and 470 $\mathrm{nm}$ when the mycoplasma preparations containing $\mathrm{NADH}_{2}$ and amytal were compared to identical preparations lacking amytal.

There was about 1 to $3 \%$ reduction of $\mathrm{NADH}$ oxidase activity in Mycoplasma strain 14 supernatant fractions after passage through $0.10-\mu \mathrm{m}$ pore size filters, compared to the same preparation after passage through $0.20-\mu \mathrm{m}$ pore size filters. Supernatant fractions of all Acholeplasma spp. lost about $5 \%$ of NADH oxidase activity by passage through $0.20-\mu \mathrm{m}$ filters.

\section{DISCUSSION}

Low and Zimkus (11) discovered two distinct $\mathrm{NADH}$ oxidase activities in supernatant frac- tions of $M$. pneumoniae after ammonium sulfate fractionation or acrylamide electrophoresis. Our data suggest the presence of two kinds of ferricyanide oxidoreductase activity in supernatant fractions of Mycoplasma strain 14 distinguished by different $K_{m}$ values. Two forms of NADH dehydrogenase have also been found in bovine heart preparations by Singer and Gutman (28). They suggested that the lower molecular weight form might be derived from the higher molecular weight form, as a result of experimental manipulation.

Possibly, the two activities we detected indicate the presence of two enzymes with different requirements for ferricyanide, or one enzyme with two distinguishable ferricyanide reaction sites, each possessing a different MichaelisMenten constant. Changes in the maximum velocity of the reaction should be directly proportional to changes in enzyme content of the reaction mixture. This was not observed upon comparing the two experiments plotted in Fig. 1. The discrepancy may be related to differences in the specific activity of the two different enzyme preparations.

The relative importance of this activity in Mollicutes is not known with certainty. In mammalian systems the primary flavoprotein dehydrogenase is the enzyme which first reoxidizes $\mathrm{NADH}_{2}$ during mitochondrial oxidative phosphorylation and leads to the generation of adenosine $5^{\prime}$-triphosphate (ATP) (27). If an analogy to the Mollicutes is valid, as the "first step" in the electron transport chain leading to ATP, examination of the NADH:ferricyanide oxidoreductase activity deserved more critical scrutiny. Furthermore, the flavin-terminated electron-transport chain in some fermentative mycoplasmas is relatively simple (see P.J. Van Demark, Fig. 4.7 in reference 29) and has fewer recognized components. Our inability to find evidence for cytochrome pigments in supernatant fractions of Mycoplasma strain 14 supports similar findings in other fermentative mycoplasmas $(6,24,29,32,35)$.

S. L. Smith (Master's thesis, Cornell University, New York, 1963) was the first to associate both NADH oxidase and a dichlorophenolindophenol diaphorase activity in high-speed supernatants of sonically treated whole cells of $\mathrm{Myco}$ plasma gallisepticum 293. Calculation of these data reveals an $\mathrm{M} / \mathrm{S}$ ratio for $\mathrm{NADH}$ oxidase activity of about 0.3 , a number compatible with the findings in this paper. However, Smith found that none of the NADH oxidase but some of the diaphorase activity would pass through a $0.1-\mu \mathrm{m}$ pore size filter. In contrast, we found that most of the NADH oxidase activity did pass through a $0.1-\mu \mathrm{m}$ pore size filter. However, 

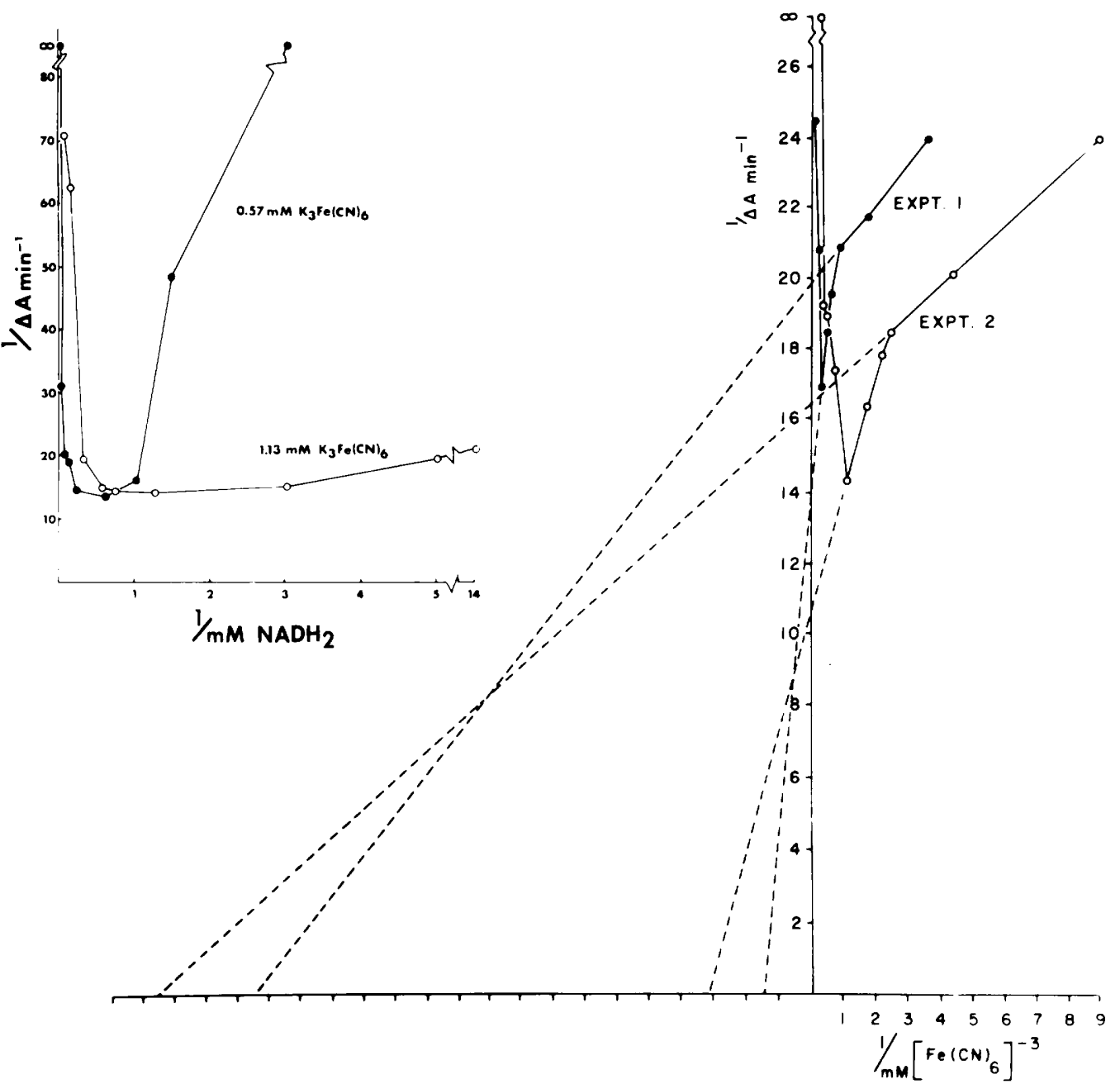

FIG. 1. Effect of $\mathrm{K}_{3} \mathrm{Fe}(\mathrm{CN})_{\mathrm{B}}$ concentration on the velocity of ferricyanide reduction using Mycoplasma strain 14 supernatant fraction concentrate at $1.50 \mathrm{mM} \mathrm{NADH}$. In experiment 1 the cuvettes contained $14 \mathrm{mg}$ of protein (O); in experiment 2 , with another batch of concentrate, the cuvettes contained $22 \mathrm{mg}$ of protein (O). Insert: Effect of $\mathrm{NADH}_{2}$ concentration on the velocity of ferricyanide reduction using Mycoplasma strain 14 supernatant fraction concentrate. In both experiments the cuvettes contained $14 \mathrm{mg}$ of protein from the same batch of concentrate. In one experiment the $\mathrm{K}_{3} \mathrm{Fe}(\mathrm{CN})_{3}$ was $0.57 \mathrm{mM}(\bullet)$; in the other experiment it was 1.13 $m M(\mathrm{O})$.

TABLE 2. Ratio of NADH:ferricyanide oxidoreductase activity in osmotically prepared membrane $(M)$ and supernatant $(S)$ fractions from Mycoplasmatales $^{a}$

\begin{tabular}{c|c|c|c}
\hline Strain & $\mathrm{M}$ & $\mathrm{S}$ & $\mathrm{M} / \mathrm{S}^{\circ}$ \\
\hline $\begin{array}{c}\text { Acholeplasma laidlawii } \\
\text { B (PG9) }\end{array}$ & 1.56 & 0.18 & 8.66 \\
\begin{tabular}{c} 
Mycoplasma strain 14 \\
\hline
\end{tabular} & 0.09 & 14.01 & 0.01 \\
\hline
\end{tabular}

${ }^{a}$ Micromoles of $\mathrm{K}_{3} \mathrm{Fe}(\mathrm{CN})_{6}$ reduced per minute per milligram of Lowry protein.

${ }^{b}$ Data are the means from three to six different batches of organisms. by conventional electron microscopy, I found (unpublished results) a few particles less than $0.1 \mu \mathrm{m}$ in diameter in this filtrate. These latter observations support the findings of S. L. Smith associating this activity with particle-containing preparations of $M$. gallisepticum 293. In any event, the filtrability or nonfiltrability of Mycoplasma species supernatant NADH oxidase activity through small pores does not obscure the apparent taxonomic usefulness of its in vitro localization.

Furthermore, Z. Ne'eman (unpublished results, cited in reference 21) has been unable to 
detect $\mathrm{NADH}$ oxidase activity in membranes from $M$. mycoides subsp. mycoides isolated by digitonin in the presence of $\mathrm{Mg}^{2+}$. These methods, it is claimed, minimize the release of loosely associated membrane proteins. The results support a cytoplasmic location for electron transport chain activity in this organism.

Awasthi et al. (1) proposed, after examining beef heart mitochondria, that the NADH dehydrogenase is joined to the membrane structure by way of cardiolipin bridges. There may be a similar lipoidal bond which links the activity to Acholeplasma membranes. This speculation requires that the effective lipid(s) of Acholeplasma membranes is absent, scanty, or modified in Mycoplasma membranes. If the lipid(s) is present in Mycoplasma membranes it suggests that the enzyme is unable to attach or that the attachment is susceptible to osmotic lysis. The idea is intriguing since P. F. Smith has shown that the presence of some lipids of these genera, almost entirely in the membrane, may be taxonomically distinguishing $(29,30)$. However, Ne'eman et al. (16) have shown that NADH oxidase activity isolated from $A$. laidlawii membranes with detergent does not require the presence of membrane lipids.

It is probable that electron microscopy histochemical procedures will clarify the question of where NADH oxidase activity is localized in Mycoplasma.

We cannot say positively that NADH oxidase activity (or activities) of Mycoplasma species is localized at the membrane level in situ, but it is clear that upon osmotic lysis it is not sedimented with membranes by our procedures. This observation is in unique distinction to all Acholeplasma species similarly examined, and separates the genus Mycoplasma from other prokaryotes (26) with the interesting exceptions of Streptococcus faecalis (9), Clostridium perfringens (8), and Bacillus subtilis (10), as noted by Low and Zimkus (11).

We have differentiated species of Acholeplasma and Mycoplasma by the in vitro localization of NADH oxidase activity in their osmotically prepared membrane and supernatant fractions. This test may be useful taxonomically and may reflect another significant distinction in the membrane architecture and physiology of these genera.

\section{LITERATURE CITED}

1. Awasthi, Y. C., R. Berezney, F. J. Ruzicka, and F. L. Crane. 1969. Action of phospholipase A on mitochondrial cristae. Biochim. Biophys. Acta 189:457-460.

2. Bak, L. B., F. T. Black, C. Christiansen, and E. A
Freundt. 1969. Genome size of mycoplasmal DNA. Nature (London) 224:1209-1210.

3. Dolin, M. I. 1959. Oxidation of reduced diphosphopyridine nucleotide by Clostridium perfringens. II. Purification of the oxidase; relation to cytochrome $c$ reductase. J. Bacteriol. 77:393-402.

4. Dolin, M., and N. P. Wood. 1960. The Streptococcus faecalis oxidase for reduced diphosphopyridine nucleotide. V. A flavin mononucleotide-containing diaphorase. J. Biol. Chem. 235:1809-1814.

5. Edward, D. G. ff., and E. A. Freundt. 1970. Amended nomenclature for strains related to Mycoplasma laidlawii. J. Gen. Microbiol. 62:1-2.

6. Freundt, E. A. 1973. Principles of Mycoplasma classification. Ann. N. Y. Acad. Sci. 225:7-13.

7. Freundt, E. A., B. E. Andrews, H. Ern $\phi$, M. Künze, and F. T. Black. 1973. The sensitivity of Mycoplasmatales to sodium-polyanethol-sulfonate and digitonin. Zentralbl. Bakteriol. Parasitenk. Infektionskr. Hyg. Abt. 1 Orig. 225: 104-112.

8. Herring, P. K., and J. D. Pollack. 1974. Utilization of $\left[1-{ }^{14} \mathrm{C}\right]$-acetate in the synthesis of lipids by acholeplasmas. Int. J. Syst. Bacteriol. 24:73-78.

9. Künze, M. 1971. Natrium-Polyanethol-Sulfonate als diagnostisches Hilfsmittel bei der Differenzierung von Mykoplasmen. Zentralbl. Bakteriol. Parasitenk. Infektionskr. 216:501-505.

10. Lightbrown, J. W., and M. Kogut. 1959. Soluble enzymes catalyzing the oxidation of reduced diphosphopyridine nucleotide by molecular oxygen and hydrogen peroxide isolated from Bacillus subtilis. Biochem. J. 73:14.

11. Low, I. E., and S. M. Zimkus. 1973. Reduced nicotinamide adenine dinucleotide oxidase activity and $\mathrm{H}_{2} \mathrm{O}_{2}$ formation of Mycoplasma pneumoniae. J. Bacteriol. 116:346-354

12. Lowry, O. H., N. J. Rosebrough, A. L. Farr, and R. J. Randall. 1951. Protein measurement with the Folin phenol reagent. J. Biol. Chem. 193:265-275.

13. Mârdh, P.-A., and D. Taylor-Robinson. 1973. The differential effect of lysolecithin on mycoplasmas and acholeplasmas. Med. Microbiol. Immunol. 158:219-226.

14. Minakami, S., R. L. Ringler, and T. P. Singer. 1962. Studies on the respiratory chain-linked dihydrodiphosphopyridine nucleotide dehydrogenase. I. Assay of the enzyme in particulate and in soluble preparations. J. Biol. Chem. 237:569-576.

15. Morowitz, H. J., and D. C. Wallace. 1973. Genome size and life cycle of the mycoplasma. Ann. N. Y. Acad. Sci. 225:62-73.

16. Ne'eman, Z., I. Kahane, J. Kovartovsky, and S. Razin. 1972. Characterization of the mycoplasma membrane proteins. III. Gel filtration and immunological characterization of Acholeplasma laidlawii membrane proteins. Biochim. Biophys. Acta 266:255-268.

17. Neimark, H. 1973. Molecular evolutionary studies on mycoplasmas and acholeplasmas. Ann. N.Y. Acad. Sci. 225:14-21.

18. Pollack, J. D., S. Razin, and R. C. Cleverdon. 1965. Localization of enzymes in Mycoplasma. J. Bacteriol. 90:617-622.

19. Pollack, J. D., S. Razin, M. E. Pollack, and R. C. Cleverdon. 1965. Fractionation of mycoplasma cells for enzyme location. Life Sci. 4:973-977.

20. Pollack, J. D., N. L. Somerson, and L. B. Senterfit. 1970. Isolation, characterization, and immunogenicity of Mycoplasma pneumoniae membranes. Infect. Immun. 2:326-339.

21. Razin, S. 1974. The mycoplasma membrane, p. 1-100. In J. F. Danielli, M. D. Rosenberg, and D. A. Cadenhead (ed.), Progress in surface and membrane science. Academic Press Inc., New York. 
22. Razin, S., and J. G. Tully. 1970. Cholesterol requirement of mycoplasmas. J. Bacteriol. 102:306-310.

23. Rodwell, A. W. 1967. The nutrition and metabolism of mycoplasma: progress and problems. Ann. N. Y. Acad. Sci. 143:88-109.

24. Rodwell, A. W., and E. S. Rodwell. 1954. The breakdown of carbohydrates by Asterococcus mycoides, the organism of bovine pleuropneumonia. Aust. J. Biol. Sci. 7:18-30.

25. Rottem, S. 1972. Differentiation of sterol-requiring from sterol-nonrequiring mycoplasmas by amphotericin B. Appl. Microbiol. 23:659-660.

26. Salton, M. R. J. 1971. Bacterial membranes. Chemical Rubber Co. Crit. Rev. Microbiol. 1:161-197.

27. Singer, T. P. 1963. Flavoprotein dehydrogenases of the electron-transport chain (survey), p. 345-381. In P. D. Boyer, H. Lardy, K. Myrbäck (ed.), The enzymes, vol. 7A. Academic Press Inc., New York.

28. Singer, T. P., and M. Gutman. 1971. The DPNH dehydrogenase of the mitochondrial respiratory chain, $p$. 79-153. In F. F. Nord (ed.), Advances in enzymology, vol. 34. Interscience Publishers, New York.
29. Smith, P. F. 1971. The biology of mycoplasmas, Academic Press Inc., New York.

30. Smith, P. F., T. A. Langworthy, and W. R. Mayberry. 1973. Lipids of mycoplasmas. Ann. N. Y. Acad. Sci. 225:22-27.

31. Smith, P. F., and G. H. Rothblat. 1960. Incorporation of cholesterol by pleuropneumonia-like organisms. J. Bacteriol. 80:842-850.

32. Smith, S. L., P. J. Van Demark, and J. Fabricant. 1963. Respiratory pathways in the Mycoplasma. I. Lactate oxidation by $M$. gallisepticum. J. Bacteriol. 86:893-897.

33. Tully, J. G. 1973. Biological and serological characteristics of the acholeplasmas. Ann. N. Y. Acad. Sci. 225:74-93.

34. Van Demark, P. J. 1967. Respiratory pathways in the mycoplasma. Ann. N. Y. Acad. Sci. 143:77-84.

35. Van Demark, P. J. 1969. Respiratory pathways in the mycoplasmas, p. 491-501. In L. Hayflick (ed.), The Mycoplasmatales and the L-phase of bacteria. Appleton-Century-Crofts, New York. 